\title{
Impacto de la Fortificación con Ácido Fólico Sobre el Estado Nutricional en Mujeres y la Prevalencia de Defectos del Tubo Neural
}

\author{
Dra. ELVIRA B. CALVO ${ }^{1}$ y Lic. ANA BIGLIERI ${ }^{1}$ \\ 1. Dirección Nacional de Maternidad e Infancia, Ministerio de Salud. Buenos Aires.
}

\begin{abstract}
Impact of folic acid fortification on women nutritional status and on the prevalence of neural tube defects
\end{abstract}

Introduction: In 2003 iron and folic acid fortification of wheat flour became mandatory in Argentina. Folate nutritional status was assessed in a national probabilistic sample of women 10-49 years old and pregnant women. Changes in the prevalence of neural tube defects (NTDs) were evaluated before and after fortification. Population and Methods: Data from the National Nutritional and Health Survey done in 2005 were used for folate intakes ( $24 \mathrm{~h}$ dietary recall) and serum levels. Fetal and infant mortality rates for NTDs were assessed in the period 2000-2006 from Vital Statistics Series, based on birth and death certificates. Prevalence of NTDs in hospital discharge statistics were analyzed in the pre and post fortification period. Results: Median folate intakes were 532 and $821 \mu \mathrm{g} /$ day in women 10-49 years-old and pregnant women, respectively. In both groups, folic acid from wheat flour represented 245 and $331 \mu \mathrm{g} /$ day. Serum folate was assessed in 5,322 women 10-49 years old and in 1,321 pregnant women. Prevalence of serum folate concentration $<3 \mathrm{ng} / \mathrm{mL}$ was $0.8 \%$ in women of child-bearing age and $2.7 \%$ in pregnant women. Mortality rate due to anencephaly in 2000-2003 was 53.1 per 100.000 births and decreased to 23.3 per 100.000 births in 2005-2006. Spina bifida mortality rate decreased $67 \%$ in the same period. In a similar way, hospital discharge statistics showed a decrease of $54 \%$ for anencephaly, 33\% for encephalocele, and 45\% for spina bifida between 2000 and 2005. Conclusions: Food fortification with folic acid was associated with adequate intakes and serum folate levels in women. Concurrently, NTDs prevalence and mortality showed a significant reduction.

(Key words: Folic acid, neural tube defects, intake, serum folate, Vitamin B12).

Arch Argent Pediatr 2008; 106 (6): 492-498/492

\section{RESUMEN}

Introducción: Se evaluó el efecto de la fortificación de la harina de trigo con ácido fólico (iniciada en 2003) sobre la ingesta de folatos en la población de mujeres en edad reproductiva y en embarazadas y los niveles séricos de folato y vitamina B12 en los mismos grupos. Asimismo, se analizaron los cambios ocurridos en 
las tasas de defectos del tubo neural antes de la fortificación y después de ella. Población y Métodos: Se analizaron datos de la Encuesta Nacional de Nutrición y Salud sobre ingesta (recordatorio de las 24 h previas) y niveles séricos de folatos y vitamina B12 en una muestra probabilística de la población de mujeres de 1049 años, incluso embarazadas, de todo el país. Se analizaron datos de mortalidad y egresos hospitalarios por defectos congénitos asociados a ácido fólico prefortificación o posfortificación en las Series de Estadísticas de Salud oficiales. Resultados: Las medianas de ingesta de folatos fueron 532 y $821 \mu \mathrm{g} / \mathrm{día}$ en mujeres de 10-49 años y embarazadas, respectivamente. La ingesta de ácido fólico de fortificación fue de 245 y $331 \mu \mathrm{g} / \mathrm{d}$ áa. Se realizaron determinaciones bioquímicas en 5.322 mujeres en edad reproductiva y 1.321 embarazadas. El 0,8\% de las mujeres y el 2,7\% de las embarazadas presentaron niveles de folato sérico menores de $3 \mathrm{ng} / \mathrm{ml}$. La tasa de mortalidad por anencefalia en el período 2000-2003 fue de 53,1 y en 2005-2006 fue de 23,3 por 100000 , con un descenso de $56 \%$. La mortalidad por espina bífida disminuyó un $67 \%$ en el mismo período. Los egresos hospitalarios del sector público en 2005 disminuyeron con respecto al 2000 en 54\% para anencefalia, 33\% para encefalocele y $45 \%$ para espina bífida. Conclusión: La fortificación de la harina con ácido fólico se asocia con ingestas y niveles séricos adecuados de folatos en las mujeres. En forma concurrente, se observa una reducción significativa en la prevalencia y mortalidad de los defectos del tubo neural.

(Palabras clave: Ácido fólico, defectos del tubo neural, ingesta, folato sérico, Vitamina B12).

Arch Argent Pediatr 2008; 106(6):492-498/492

ESTE TRABAJO LO PUEDE ENCONTRAR EN EXTENSO EN WWW.SciELO.ORG 